
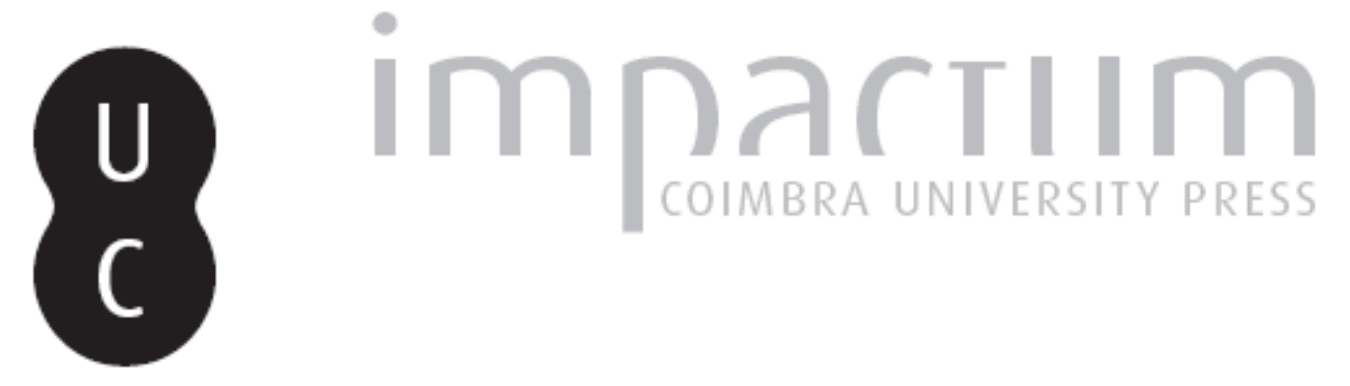

\title{
De Andrea Sansovino a Filippo Terzi: hesitações da casa real portuguesa
}

Autor(es): $\quad$ Tavares, Domingos

Publicado por: Imprensa da Universidade de Coimbra

URL persistente:

URI:http://hdl.handle.net/10316.2/44973

DOI:

DOI:https://doi.org/10.14195/0870-8584_12_10

Accessed : $\quad$ 26-Apr-2023 16:30:23

A navegação consulta e descarregamento dos títulos inseridos nas Bibliotecas Digitais UC Digitalis, UC Pombalina e UC Impactum, pressupõem a aceitação plena e sem reservas dos Termos e Condições de Uso destas Bibliotecas Digitais, disponíveis em https://digitalis.uc.pt/pt-pt/termos.

Conforme exposto nos referidos Termos e Condições de Uso, o descarregamento de títulos de acesso restrito requer uma licença válida de autorização devendo o utilizador aceder ao(s) documento(s) a partir de um endereço de IP da instituição detentora da supramencionada licença.

Ao utilizador é apenas permitido o descarregamento para uso pessoal, pelo que o emprego do(s) título(s) descarregado(s) para outro fim, designadamente comercial, carece de autorização do respetivo autor ou editor da obra.

Na medida em que todas as obras da UC Digitalis se encontram protegidas pelo Código do Direito de Autor e Direitos Conexos e demais legislação aplicável, toda a cópia, parcial ou total, deste documento, nos casos em que é legalmente admitida, deverá conter ou fazer-se acompanhar por este aviso. 


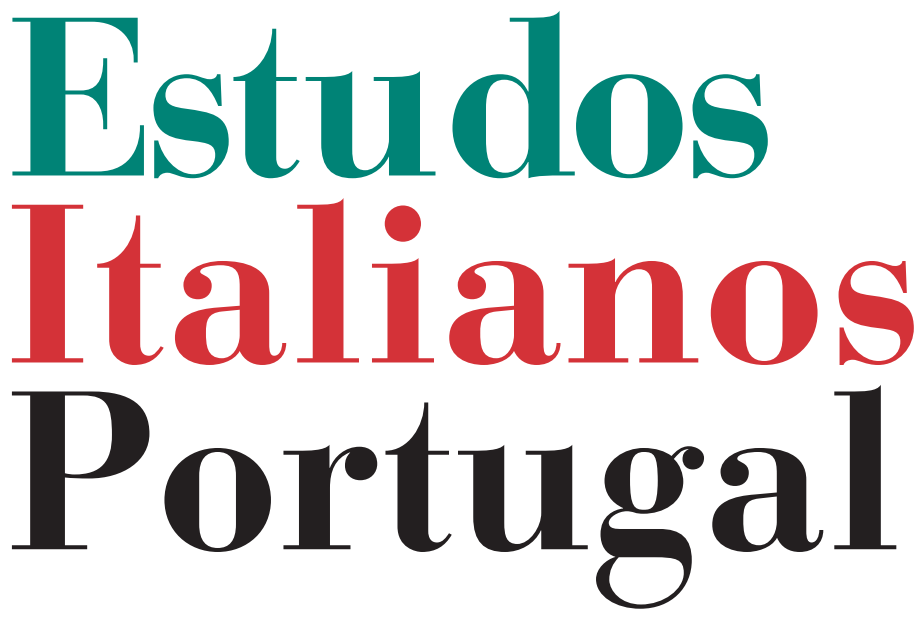

Instituto

Italiano

de Cultura

de Lisboa

Nova Série

No 12

2017 


\title{
DE ANDREA SANSOVINO A FILIPPO TERZI. HESITAÇÕES DA CASA REAL PORTUGUESA
}

\author{
DOMingos TAVAREs*
}

A questão dos artistas italianos em Portugal coloca-se de modo sistemático acompanhando os processos de transformações da cultura europeia que acompanharam a expansão do classicismo. Processo iniciado em Florença de onde se estendeu num primeiro momento e seguido por Roma numa segunda fase. Uma cultura que era a expressão da nova sociedade tomada pelo capital financeiro (os banqueiros da Europa), com a montagem de novas estruturas de poder centralizado nas casas bancárias, controlando o comércio marítimo internacional. Do outro lado Portugal constituiu-se como país virado ao mar, com a tradição herdada dos fenícios de circular pelo Mediterrâneo, passando com regularidade as colunas de Hércules. Assim, não se estranha que a Ibéria, incluindo a sua parte Atlântica, se considerasse tão perto, física e culturalmente, das repúblicas marítimas do mar Tirreno, com destaque para Génova e Florença via Pisa.

A revolução da burguesia urbana que colocou $\mathrm{D}$. João I na gestão do reino, consolidou o país no benefício do comércio marítimo, gerando riquezas substantivas para uma gestão do Estado mais centralizado e eficaz, com margem apetecível para a casa particular do rei ou dos seus príncipes. Em boa

* Arquitecto, Professor emérito e coordenador de Investigação (Grupo Atlas da Casa - Erudito e popular na arquitectura portuguesa) no Centro de Estudos de Arquitectura e Urbanismo da Faculdade de Arquitectura da Universidade do Porto. domingos@dafne.pt 
parte, estes capitais foram colocados à guarda dos banqueiros de Florença, com destaque para a acção diplomática de D. Pedro, primeiro Infante, depois como regente do reino. Difícil foi resgatar esses dinheiros na divisão da herança do príncipe falecido, que conduziu a uma solução de recurso para que nem todos os dinheiros fossem perdidos. Uma parte desse valor foi investido na construção da capela tumular do Cardeal D. Jaime, um dos herdeiros, construída a partir de 1460 na igreja de S. Miniato al Monte pela oficina dos irmãos Rosselini, de Florença. A arquitectura foi devida a Bernardo, a execução a Giovanni e a escultura da responsabilidade de António, numa empresa em que participaram outros notáveis artistas colaboradores habituais dos Rosselino, como foi o caso de Luca della Robbia ${ }^{1}$.

Pode entender-se este episódio de grande relevo para a arte do Renascimento como um primeiro sinal da colaboração de um arquitecto da vanguarda italiana com a nação portuguesa, Bernardo Rosselino, da confiança de Leon Battista Alberti e autor da mais importante operação urbana da iniciativa do Papa Pio II como foi a reconstrução do núcleo central de Pienza. Era a homenagem póstuma a um jovem príncipe, sobrinho de Afonso V, e materializou-se no território florentino num claro sinal da abertura ao espírito do moderno por parte das autoridades portuguesas, quando no ocidente europeu predominavam as variantes do gótico final. A iniciativa destaca a sensibilidade do rei para uma nova linguagem de tendência italianizante, maior clareza e simplicidade formal, como se expressou também no apoio a obras em Ourém e Tomar, iniciadas por volta de $1450^{2}$.

Este episódio marca um momento de forte relação entre as autoridades portuguesas e o ambiente artístico em Flo-

\footnotetext{
${ }^{1}$ Mendes Atanázio, A arte em Florença no séc. XV e a capela do Cardeal de Portugal, Lisboa, Imprensa Nacional, 1983.

${ }^{2}$ Paulo Pereira, História da arte portuguesa, Lisboa, Círculo de Leitores, 1995, vol. 2, p. 27.
} 
rença na segunda metade de Quatrocentos, com intervenção activa de algumas personalidades do clero representando os interesses da família real. Estes contactos traduzem, também, o interesse pelo movimento de modernização das linguagens arquitectónicas que outros reinos do espaço europeu ocidental vinham ensaiando, enquanto processo de superação das tradiçóes medievais, acompanhando um novo quadro social e político. Foi por força da simpatia de alguns senhores europeus, particularmente em França, e da influência dos cardeais mais ilustrados frequentadores dos círculos de Roma, que se intensificou no final de Quatrocentos uma moda "ao antigo", instalada sobre as velhas práticas construtivas ${ }^{3}$.

Nas primeiras décadas do ciclo edificatório empreendido pela monarquia burguesa, coube aos mestres construtores integrados nas estruturas das corporações medievais que controlavam os sistemas produtivos, sob tutela dos príncipes, darem corpo aos programas de edificar. Em Portugal, como em outros estados da Europa mediterrânica, a progressiva consolidação de um sistema político assente na gestão centralizada da coisa pública sob a autoridade do rei, favoreceu a solidez da monarquia católica e levou a que as iniciativas de realização das artes de afirmação simbólica sob patrocínio régio, imbuídas da mesma preocupação de conferir dignidade ao estado, integrasse com o mesmo peso os monumentos religiosos e as outras arquitecturas de natureza civil.

Com o incremento das iniciativas construtivas chegavam artífices recomendados de outras terras da península, ou mesmo de França, em resposta a pretensões mais abertas da inteligência da corte, mas também de outros encomendadores, onde se destacavam bispos, nobres familiares de bispos e outros personagens proeminentes do círculo do poder. Artífices destacados nas áreas da construção, por vezes estudiosos e cultos tendo participado em experiências diversas pelas ter-

${ }^{3}$ Domingos Tavares, Philibert Delorme, profissão de arquitecto, Porto, Dafne Editora, 2004, p. 18. 
ras da sua aprendizagem, esboçavam respostas à vontade de inovação manifestada pelos dignitários patrões, quase sempre viajados e ciosos da necessidade de mudança. Assim se foi estruturando um corpo profissional que lentamente abriu escola de aproximação ao clássico dando lugar, nas gerações seguintes, ao aparecimento de jovens formados mais no estrangeiro do que nas próprias obras, quase sempre nos estaleiros de Roma.

Revelados como artistas de qualidade, passavam a adquirir a condição de bolseiros a expensas do rei, para que no regresso pudessem integrar novas ideias e saberes na reformulação das artes em Portugal. Surgiu até a condição de se poder atingir a nobreza pelo serviço da arte, acompanhando o percurso de consolidação do modo clássico, por analogia com o prestígio reconhecido a alguns criadores italianos disputados pelas casas ducais de Itália, pela cúria em Roma, ou outros requisitados para as cortes do imperador Carlos V na Bélgica ou de Francisco I em França. Por analogia com os herdeiros mesteirais do saber fazer, a classe dirigente em Portugal integrou também gente saída do corpo dos fidalgos próximos da corte, através do reconhecimento de habilidades próprias de alguns jovens particularmente dotados.

$\mathrm{O}$ país protegeu uma classe de criadores intelectuais, nas artes como na ciência, que contribuiu para o processo de consolidação da estética renascentista. Instalou-se a óptica de resposta à afirmação de uma cultura aberta ao mundo pela recepção dos comércios e trocas inerentes aos descobrimentos marítimos, pela expansão do conhecimento geográfico e pela definição de uma ciência de representação cartográfica. Constituiu esta a grande síntese da contribuição portuguesa para a consolidação civilizacional do ocidente europeu. Portanto, aqui também se colocaram as questóes do entendimento da linguagem clássica enquanto testemunho dos valores emergentes na sociedade de tendência desenvolvimentista, burguesa, de afirmação de qualidades e poderes novos, legí- 
veis por analogia com o contexto civilizacional do mediterrâneo antigo. Que arquitecturas, que arquitecto, que práticas testemunham esse momento de mudança em Portugal?

É neste quadro que se pode entender a chegada do escultor e arquitecto Andrea Sansovino. Dela nos dá notícia Giorgio Vasari, no texto que lhe é dedicado nas "Vidas" ${ }^{4}$. Apesar das inúmeras controvérsias que se têm levantado a propósito da acção concreta desempenhada pelo autor florentino durante a sua estadia em Portugal, o texto do biógrafo italiano constitui uma informação segura. No contexto da criação de um primeiro e inédito dicionário biográfico de artistas no século XVI, é reconhecido o esforço de Vasari, para ser rigoroso na descrição dos passos dos seus biografados, cujos limites de rigor são os naturais de qualquer pesquiza histórica com desfasamentos temporais de perto de um século. Sobre Andrea Contucci, nascido em Monte San Savino, Arezzo, em 1467, diz Vasari que foi enviado a Portugal por Lorenzo de Medici a pedido do nosso rei.

Está confirmada a sua chegada em 1492 e, numa primeira fase, trabalhou no espaço da corte para D. João II. Segundo Vasari teria realizado alguns trabalhos de escultura e arquitectura, referindo mesmo um belíssimo palácio com quatro torres e muitos outros edifícios, suportando a sua afirmação na consulta pessoal do caderno de desenhos do artista biografado, então na posse de um dos seus discípulos. Rafael Moreira estudou com critério a passagem de Sansovino por Portugal, considerando eventuais obras desaparecidas e até que se retirou definitivamente para Florença e Loreto em $1501^{5}$. A morte do rei em 1495 e a mudança de orientação artística promovida pelo sucessor, pode ter estado na base da

${ }^{4}$ Giogio Vasari, Le vite dei più eccellenti pittori, scultori e architetti, Roma, Newton Compton, 2004, p. 670. Publicado em primeira edição em 1550, o texto foi revisto e aumentado na 2. ${ }^{\mathrm{a}}$ ed. de 1568.

${ }^{5}$ Rafael Moreira, "Arquitectura: Renascimento e classicismo", in História da Arte Portuguesa, vol. 2, pp. 313-315. 
afirmação de Vasari que refere a dificuldade do artista italiano perante as coisas extravagantes e a arquitectura difícil que teve de enfrentar. Esta referência pode ter correspondido a uma retirada após 1495 e um segundo período, mais curto, da presença de Sansovino em Portugal, que terá voltado entre 1500 e 1501, período em que terá enfrentando definitivamente a impossibilidade de corresponder à poderosa expansão do manuelino como expressão de um gótico final.

A arte portuguesa, ao tempo de D. João II, ensaia uma sensibilidade modelada pelo padrão de fazer clássico, "ao romano", numa linha de ruptura imposta pela corrente triunfante nas repúblicas marítimas do espaço mediterrânico contra o fazer moderno de tipo germano-gótico prevalecente na Europa do norte. Uma atitude capaz de levar à objectivação os novos monumentos, oferecendo a ideia global da forma suportada pelo instrumento técnico de comunicação das intençôes projectuais para que os construtores, executantes de uma vontade predefinida, pudessem levar a termo a realização da obra. Concretização do princípio de distinção entre o trabalho intelectual próprio das artes liberais, como o caracterizou Alberti e a artesania de classificação mecânica prevalecente no quadro da sociedade medieval.

O Hospital Real de Todos os Santos, em Lisboa, foi a obra que melhor assinalou as hesitações no quadro da transição para o século dos descobrimentos, o que ficou conhecido como Hospital dos Pobres. Foi um indicativo forte da passagem do modo antigo de pensar a construção para outro tempo, de dinâmicas culturais cruzadas entre a notícia de um clássico novo e as versões modernas da arte urbana dos burgos do mar do norte, mais enfática e decorativa. Ao tomar a iniciativa de reunir o rendimento dos inúmeros pequenos hospitais de Lisboa, o rei estava a optar pela acção administrativa própria de uma estrutura organizada no âmbito de um Estado centralizado. Atento à corrente italiana da corte de Lorenzo de Médici e ao exemplo do hospital de Santa 
Maria Nova, de Florença, cujo trato brilhante como campo teórico teve expressão no Hospital dos Pobres de Milão, parcialmente realizado e depois divulgado nas cortes clássicas pelas versões manuscritas do tratado de Filarete a partir de $1465^{6}$.

Para a concretização do projecto do hospital dos pobres foi chamado Mateus Fernandes, mestre das obras do Mosteiro da Batalha e disciplinado executante de programas complexos e inovadores como fora o Hospital das Caldas e a sua igreja, da iniciativa da raínha $\mathrm{D}$. Leonor. Lídimo representante da invocação técnica do período tardo-gótico para a montagem da linguagem áulica que foi o nacionalismo manuelino, começou por esboçar a transferência de um programa funcional oriundo de Itália, a que se sucedeu a imposição de elementos formais para consolidação de uma imagem artística que fosse ao modo de Portugal. ${ }^{7}$ O Hospital Real em Lisboa surgiria como primeira expressão de uma prática de importação do fazer italiano entre Florença e o ducado de Milão, modelo que seria replicado depois em Santiago de Compostela, Toledo, Granada e Sevilha.

Diogo Boitaca dar-lhe-ía a mais pura feição manuelina com exibição frontal da fachada da igreja. Este mestre Boitaca, provavelmente oriundo do sul de França onde persistia alguma tradição do fazer "ao romano", chegou a ser dado como italiano, numa visão distorcida do cruzamento das influências estrangeiras, normandas, flamengas, francesas, que carregaram complexidades sobre o chamado estilo nacional, ou Manuelino. É curioso observar que a chamada ruptura manuelina de cariz nacionalista que interrompeu as experiências iniciais de aproximação ao clássico, tenha sido interpretada em boa parte por mestres estrangeiros que se estabe-

${ }^{6}$ Michele Lazzaroni; Antonio Munoz, Filarete, scultore e architetto del secolo XV, Roma, W. Modes Editore, 1908, pp. 236-241.

${ }^{7}$ Vítor Serrão, História da arte em Portugal. O Renascimento e o Maneirismo, Lisboa, Editorial Presença, 2001, p. 23. 
leceram no país. Foi o caso de Boitaca, mas também de João e Diego Castilho, importados de França ou de Castela.

Boitaca, os irmãos Arruda, como outros mestres construtores ao serviço do rei, acompanharam as campanhas militares em África. As novas artes da guerra associadas ao desenvolvimento da engenharia militar, particularmente na organização defensiva das praças conquistadas ao longo da costa Atlântica, agudizaram os saberes da nova geração de construtores. Estavam em curso novas descobertas envolvendo as artes da guerra, com solicitação premente a alterações dos sistemas construtivos como foram o desenvolvimento do sistema abaluartado e do tiro baixo controlado por estudos de geometria. As acções militares nos constantes conflitos entre os Estados italianos, como na defesa sob as invasões otomanas, teve uma enorme participação dos mais notáveis arquitectos italianos, consolidando o seu prestígio entre a inteligência portuguesa.

Foi, então, no contexto da expansão marítima e na estruturação de um saber militar operativo, que as autoridades portuguesas se empenharam em mobilizar a contribuição dos experientes desenhadores de fortalezas que foram surgindo nas corporações de construtores, recorrendo quanto possível a conhecimentos percebidos pela nobreza que participou nas guerras contra os turcos. As questóes formais do medievalismo foram dando lugar às competências técnicas no processo construtivo, movimento que culminou com a acção do príncipe D. Luís, irmão de D. João III, um verdadeiro perito na arte militar que convocou a colaboração do engenheiro Benedetto de Ravenna para a criação de um sistema de fortalezas modernas traçadas à semelhança das que então se faziam em Itália. ${ }^{8}$

A propósito da vinda de especialistas italianos, peritos em construção militar, importa repor a discussão sobre o entendimento das diferenças entre arquitectos e engenheiros nesses

\footnotetext{
${ }^{8}$ Rafael Moreira, cit., vol. 2, p. 331.
} 
primeiros períodos do desenvolvimento moderno do país. No primeiro ciclo artístico do Renascimento italiano, não se considera uma distinção clara entre pintores, escultores e arquitectos. A figura do arquitecto começa a impor-se na cultura das cidades com a compreensão de alguma especificidade dos métodos de desenho nos processos de criação envolvendo a necessidade de projecto. Esta faceta, sendo igualmente reconhecida nas outras artes visuais, ganhou premência nos processos construtivos em face da ruptura com as práticas de repetição medieval. Foi no contexto das sucessivas clarificaçôes profissionais, com o incremento do rigor no desenho das máquinas defensivas como aconteceu com as novas fortalezas (invenção do baluarte, da casamata, etc.), que os arquitectos incrementaram o saber técnico específico apoiado na geometria e na física, à procura da resposta eficiente.

Leonardo da Vinci, Giuliano da Sangallo ou Francesco di Giorgio Martini, seguraram o seu prestígio de artistas como arquitectos, mas já Benedetto de Ravenna foi tomado como arquitecto e engenheiro militar, porque se especializou nas construções ao serviço da guerra desenhando fortificações. Trabalhando para os espanhóis do reino de Nápoles, seguiuos nas campanhas da Lombardia e do Mediterrâneo, fixandose ao serviço do rei de Castela. Em Portugal apoiou a estratégia seguida por D. João III, no sentido de consolidar as posiçôes de apoio à rota do comércio atlântico, desenhando soluções e orientando os construtores do reino na execução das fortalezas marítimas em África, de que o mais notável exemplo foi a cidadela portuária de Mazagão.

Essa seria, também, a especificidade da acção de Filippo Terzi ao serviço do rei de Portugal, remontando as primeiras notícias da sua presença no reino ao tempo de D. Sebastião, com a sua participação na campanha militar a Alcácer Quibir na qualidade de desenhador de armações militares mó-

\footnotetext{
9 Jorge Correia, Implantação da cidade portuguesa no Norte de Africa, Porto, FAUP, 2008, pp. 336-343.
} 
veis. Nessa condição, já não o tomamos como o arquitecto clássico no sentido corrente. D. João III, e os príncipes seus irmãos tomavam definitivamente o caminho da arquitectura clássica, ao modo romano, e instruíam os seus melhores servidores para cumprir o sonho pessoal, porque todos eles se consideravam capazes da arquitectura. Não importaram arquitectos de Itália, antes enviavam os jovens mais talentosos a Roma para aprender o ofício de inventar a forma moderna que queriam para enaltecer as suas próprias realizaçóes. Os arquitectos da casa real eram portugueses. Terzi chegou a Portugal na lógica do engenheiro militar.

Sob a protecção de D. Sebastiāo e, posteriormente, do cardeal-rei, António Rodrigues foi mesmo o primeiro arquitecto português de base científica, para expressar o movimento colectivo com reflexos nas artes em geral e na arquitectura de modo particular. Outros se destacaram na geração de quinhentos depois de estágios mais ou menos prolongados em terras de Itália, aprofundando seus saberes mesmo quando eram herdeiros espirituais de notáveis construtores agentes da transição do período manuelino para a linguagem clássica. Como Miguel de Arruda ou Jerónimo Ruão. É que Rodrigues foi um leitor crítico dos conceitos formulados nos tratados maneiristas que correram na sua época, propondo, como autor do primeiro tratado de arquitectura escrito em português, o enunciado teórico adequado ao humanismo neoplatónico em expansão nos meios intelectuais próximos da corte. Organizou os princípios de uma sintaxe clássica, erudita, submetida ao controlo da composição pela razão, colocando o rigor geométrico e a expressão do essencial acima dos efeitos decorativos que tão fortemente caracterizaram a época anterior ${ }^{10}$.

Filippo Terzi, que era natural de Bolonha onde nasceu em 1520, trabalhou em Urbino e Roma e em 1577 já se encon-

${ }^{10}$ Domingos Tavares, António Rodrigues, Renascimento em Portugal, Porto, Dafne Editora, 2007, p. 11. 
trava em Lisboa, ao serviço de D. Sebastião, para cumprir um programa de renovar as fortalezas da costa portuguesa. Foi feito cativo na derrota militar de Alcácer Quibir, onde acompanhou o rei na sua primeira e última aventura africana. Levava como função desenhar e acompanhar a execução de armações moveis militares em contexto de batalha. A importância que lhe era atribuída pode medir-se pelo empenho do Cardeal D. Henrique, tio do rei morto e rei de reinado breve, que mandou iniciar diligências para que este engenheiro, homem útil ao serviço da sua profissão, fosse resgatado. A partir de então, ou já no quadro da união dinástica sob a autoridade de Filipe de Espanha, Terzi ganhou posição enquanto servidor do Estado.

As suas atribuiçôes mantêm-se ligadas à competência técnica de construtor na área militar, de que se conhecem a Fortaleza de São Filipe em Setúbal ou o forte de cinco baluartes na Foz do Rio Ave, em Vila do Conde. Foi frequentemente enviado a examinar obras de pontes ou a realizar infraestruturas como o aqueduto de abastecimento ao Convento de Santa Clara em Vila do Conde. Em 1584 foi nomeado mestre das obras do Convento de Cristo em Tomar, ocupando-se da construção do aqueduto e ainda em 1589 se encontrava em Peniche dirigindo trabalhos de fortificaçãa. Foi só em 1590, por morte do arquitecto António Rodrigues, que Filipe o nomeou mestre de todas as obras que se fizessem à custa da fazenda do rei. Terá, então, surgido algum reconhecimento de Terzi como arquitecto, quando quatro anos depois toma o lugar de professor oficial de arquitectura. Era então mestre das obras das Ordens de Santiago, tendo permanecido nestes cargos até à sua morte em $1597^{11}$.

Do pré-renascimento de D. João II e sucessivo nacionalismo gótico-tardio de $\mathrm{D}$. Manuel, passou-se a um internacio-

${ }^{11}$ Francisco de Sousa Viterbo, Dicionário histórico e documental dos arquitectos, engenheiros e construtores portugueses, Lisboa, Imprensa Nacional - Casa da Moeda, 1988, vol. 2, pp. 93-101 [reed. facsimilada ed. 1922]. 
nalismo em coerência com as casas reais dos Habsburgo, que pretendiam ser mais flamengos que clássicos e conduziu, em Portugal, a uma ambiguidade estilística dificilmente superada. No final do percurso que integrou o nosso renascimento áulico, constata-se alguma marginalidade da intervenção directa dos artistas italianos chamados ao país. Num primeiro momento, Andrea Sansovino não teve condições de impor o modo novo da rica Florença, frente à natural e característica resistência das corporaçōes dos ofícios, instalados numa forte lógica medieval. Pelo caminho, ultrapassado um tempo de novo-riquismo despesista das especiarias douradas, foi o sentimento de autossuficiência dos príncipes, que não quiseram abdicar do controlo da expressão artística que os motivava. E outras histórias foram marginalizadas porque escaparam à simpatia dos irmãos de D. João III, como foi o caso de Francesco de Cremona, tratado noutro contexto e limitado aos espaços do norte e da região do Porto.

Apenas quando Filipe, senhor absoluto da União dos Reinos, apoiado em Juan de Herrera seu aposentador e arquitecto matemático, se sentiu seguro do mando que podia exercer, Filippo Terzi pode beneficiar do estatuto de arquitecto. Só então, em fim de vida, se abriu espaço para o exercício pleno da arquitectura a um autor italiano que dedicou vinte anos de actividade profissional à arte de construir em Portugal. Não vale atribuir-lhe autorias estranhas como o Claustro Grande de Tomar ou a Igreja do Mosteiro de São Vicente de Fora. Outras foram as suas tarefas. Sobrou, sim, fora do âmbito das fortalezas militares e outras infraestruturas como pontes e aquedutos, a Igreja do Convento de Palmela da Ordem de Santiago, iniciada no ano anterior à sua morte. 